\title{
A Quasi Experimental Study to Compare the Effect of Semi-Sitting Versus Left Lateral Position on Maternal and Foetal Bio-Physiological Parameters Among Antenatal Women Undergoing Non Stress Test in Tertiary Care Hospital of Patiala, Punjab
}

\author{
GURPREET KAUR ${ }^{1, *}$ PREETY NARULA ${ }^{2}$, HARPREET KAUR $^{3}$ \\ ${ }^{1}$ Msc.(N) student, Deptt. of Obstetric and gynaecological Nursing, Giansagar College \\ of Nursing, Ram Nagar, Rajpura, Patiala, Punjab. \\ ${ }^{2}$ Assistant Professor, Deptt. of Obstetric and gynaecological Nursing, Giansagar \\ College of Nursing, Patiala, Punjab.
}

${ }^{3}$ Associate Professor, Deptt. Obstetric and gynaecological Nursing, Giansagar Medical

College and Hospital, Patiala, Punjab.

Email: kaur.gurpreet@chitkara.edu.in

Received: June 02, 2017 | Revised: July 12, 2017 | Accepted: August 22, 2017

Published online: October 02, 2017

The Author(s) 2017. This article is published with open access at www.chitkara.edu.in/Publications

\section{Background of the study}

NST is a simple, non invasive test performed in pregnancy over 28 weeks of gestation. Pregnant women are generally positioned in the supine position because this position allow easy administration of the test. But supine position cause aortacaval compression which decrease blood supply to the fetus hence shows non reactive results. Hence position is one of the main factor which should be considered during non stress test.

\section{Methodology}

Aquasi experimental design was used. Total 60 antenatal women (30 experimental group I, 30 experimental group II) was selected by purposive sampling technique. Data collection method- Baseline maternal foetal bio-physiological parameters were assessed by performing NST for 10 minutes in baseline position(supine position) among experimental groups and then after a gap of 10 minutes semi-sitting and left lateral position was given to experimental group I and II respectively. Maternal and foetal bio-physiological parameters were assessed after 10 minutes of NST in both experimental groups I and II.

\footnotetext{
Journal of Multidisciplinary Research in Healthcare Vol-4, No-1, October 2017 pp. 51-66
} 
Kaur, G

Narula, P

Kaur, $\mathrm{H}$

\section{Results}

Result of the present study revealed that baseline (supine) when compared with Semi-sitting position had significant effect on maternal foetal bio-physiological parameters at $(\mathrm{p}<0.05)$ level of significance however when baseline (supine) compared with left lateral position had no significant effect on maternal biophysiological parameters except on pulse rate at $(\mathrm{p}<0.05)$ level of significance whereas left lateral position had significant effect on foetal bio-physiological parameters except baseline heart rate and deceleration at $(\mathrm{p}<0.05)$ level of significance. When semi-sitting compared with left lateral had no significant effect on maternal foetal bio-physiological parameters at $(\mathrm{p}<0.05)$ level of significance.

\section{Conclusion}

Baseline position(supine) when altered to semi-sitting or left lateral position influence the maternal foetal bio-physiological parameters. Semi-sitting when compared with left lateral had no significant effect on maternal and foetal biophysiological parameters

Keywords: NST, physiological, parameters, maternal, foetal, position.

\section{INTRODUCTION}

Antenatal care is one of the important element to ensure normal pregnancy with delivery of healthy baby. There are many ways to evaluate the health and well-being of a developing baby (fetus) throughout pregnancy. Fetal heart rate is an integral part of fetal surveillance. Auscultation of fetal heart rate has been a standard component of each prenatal visit. Monitoring fetal heart rate pattern is called non stress test ${ }^{1}$.Non stress test : In non stress test, a continuous electronic monitoring of foetal heart rate along with recording of foetal movements (cardiotocography) is undertaken. The non stress test (NST) is a primary foetal surveillance tool. The foetal NST is a simple, non invasive test performed in pregnancy over 28 weeks of gestation. Before 28 weeks, the fetus is not developed enough to respond to the test protocol. The test is named "non stress" because no stress is placed on the foetus during the test ${ }^{2}$.

NST is a non invasive method used to evaluate foetal well-being. This test is a part of cardiotocography(CTG) used within at least 20 minutes after admission of patient, is the only screening test for evaluation of foetal well being during delivery ,important component of NST are baseline foetal heart rate (FHR), baseline variability, acceleration and deceleration ${ }^{3}$. NST records the FHR and the interaction between the foetal movements. Thereby, provides information on the health of the foetus ${ }^{4}$. NST is used in an attempt to reduce the incidence of the foetal compromise at birth i.e the result of placental insufficiency. 
Several factors can contribute to false-positive result and increase the time spent performing tests. Maternal position during NST surely influences the hemodynamic of maternal and feto-placental circulation. However, the maternal position during the testing is important element that should be part of practice guidelines. Physicians generally position the pregnant women in the supine position because this position allows easy administration of the test ${ }^{5}$.

A study done in New York, to determine whether maternal posture (left lateral recumbent vs semi-fowlers position) had an effect on non stress test results. The result shows that there was more non reactivity in supine position $(p=0.01)$. So as per findings, it was recommended that semi-fowlers position is superior position for conducting a non stress test in a short period ${ }^{6}$.

The study was conducted to assess the effect of three positions on maternal foetal biophysical parameters. The finding shows that in semi-fowlers position $69 \%$ of test was reactive and in left lateral $63.6 \%$ were reactive. So, they concluded that there is a relation between maternal position and non stress test and semi-fowlers position is a superior position for conducting non stress test ${ }^{7}$.

Studies show that left lateral and sitting position are preferable but it is still an open question regarding the best position during non stress test.These view points motivate the investigator to compare the effect of semi-sitting versus left lateral position on maternal and foetal bio-physiological parameters among antenatal women undergoing non stress test.

\section{MATERIALS AND METHODS}

A quasi experimental study was carried out by using a parallel comparative design.Total 60 antenatal women (30 experimental group I, 30 experimental group II) was selected by purposive sampling technique.The purpose of the study was explained and consent was taken from the sample. The data was collected using observational recording for assessing maternal parameters and observational checklist for assessing foetal parametersfrom 1March, 2016 to 31March, 2016. Baseline maternal foetal bio-physiological parameters were assessed by performing NST for 10 minutes in baseline position(supine position) among experimental groups. Then after a gap of 10 minutes semisitting and left lateral position was given to experimental group I and II respectively. Maternal and foetal bio-physiological parameters were assessed after 10 minutes of NST in both experimental groups I and II. Approval of research/Ethical committee of GianSagar Hospital was taken before starting the study. Permission was obtained from Nitin Hospital, Patiala, Punjab. Analysis and interpretation of data was based on objectives and was done by descriptive /inferential statistics.
A Quasi

Experimental Study to Compare the Effect of SemiSitting Versus Left Lateral Position on

Maternal and Foetal

Bio-Physiological

Parameters Among Antenatal Women Undergoing Non Stress Test in Tertiary Care Hospital of Patiala, Punjab

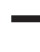


Kaur, G

Narula, P

Kaur, H

\section{ANALYSIS AND INTERPRETATION OF DATA}

\section{Section- A}

\subsection{Socio-demographic variables}

Table 1 shows that majority of antenatal women $53.3 \%$ belongs to $18-25$ years age group and $46.7 \%$ belongs to $26-33$ years in experimental group I and II respectively. In period of gestation majority of women $56.7 \%, 43.3 \%$ belong to 33-38 weeks of gestation in experimental group I and II respectively whereas minimum $16.7 \%$ belong to $39-42$ weeks in experimental group I and $26.7 \%$ belong to $28-32$ weeks of gestation in experimental group II. Majority $70.0 \%, 66.7 \%$ were primi-gravida and $30.0 \%, 33.3 \%$ were multi-gravid in experimental group I and experiment group II respectively. Majority $76.7 \%$, $66.7 \%$ were housewife and minimum $6.7 \%, 13.3 \%$ were government employee in experimental group I and experimental group II respectively. Majority $46.7 \%$ antenatal women having weight $46-55(\mathrm{~kg}), 56-65(\mathrm{~kg})$ in experimental group I and II and minimum $6.7 \%, 3.3 \%$ antenatal women having weight $35-$ $45(\mathrm{~kg})$ in experimental group I and II respectively.

$$
\mathbf{N}=\mathbf{3 0}+\mathbf{3 0}
$$

Table 1: Frequency, Percentage distribution and homogeneity of sociodemographic variables.

\section{Socio-demographic variableAntenatal women}

Exp.group IExp.group II

\begin{tabular}{lcccccc}
\multicolumn{1}{c}{$\mathbf{f}$} & $\boldsymbol{\%}$ & $\mathbf{f}$ & $\boldsymbol{\%}$ & $\mathrm{X}^{2} \mathbf{d f}$ & & \\
\hline $\begin{array}{l}\text { 1) Age (in years) } \\
\text { a) } 18-25\end{array}$ & 16 & 53.3 & 16 & 53.3 & $0.000^{\mathrm{NS}}$ & 1 \\
b) $26-33$ & 14 & 46.7 & 14 & 46.7 & & \\
c) $34-41$ & 0 & 0 & 0 & 0 & & \\
d) $>41$ & 0 & 0 & 0 & 0 & & \\
\hline 2) Period of gestation(weeks) & & & & & \\
\hline a) $28-32$ & 8 & 26.7 & 8 & 26.7 & $1.676^{\mathrm{NS}}$ & 2 \\
b) $33-38$ & 17 & 56.7 & 13 & 43.3 & & \\
c) $39-42$ & 5 & 16.7 & 9 & 30.0 & & \\
3) Gravida & & & & & & \\
a) Primi-gravida21 & 70.0 & 20 & 66.7 & $0.077^{\mathrm{NS}}$ & 1 \\
b) Multigravida & 9 & 30.0 & 10 & 33.3 & & \\
\hline
\end{tabular}




\begin{tabular}{|c|c|c|c|c|c|c|}
\hline \multicolumn{7}{|l|}{ 4) Occupation } \\
\hline a) Housewife & 23 & 76.7 & 20 & 66.7 & $0.967^{\mathrm{NS}}$ & 2 \\
\hline $\begin{array}{l}\text { b) Government } \\
\text { employee } 2\end{array}$ & 6.7 & 4 & 13.3 & & & \\
\hline c) Private employee & 5 & 16.7 & 6 & 20.0 & & \\
\hline \multicolumn{7}{|c|}{ 5) Body mass index(kg) } \\
\hline a) $35-45$ & 2 & 6.7 & 1 & 3.3 & $0.841^{\mathrm{NS}}$ & 3 \\
\hline b) $46-55$ & 14 & 46.7 & 12 & 40.0 & & \\
\hline c) $56-65$ & 12 & 40.0 & 14 & 46.7 & & \\
\hline d) $>65$ & 2 & 6.7 & 6 & 10.0 & & \\
\hline
\end{tabular}

Mean Age - 30.13 years NS- not significant

A Quasi

Experimental Study to Compare the Effect of SemiSitting Versus Left Lateral Position on Maternal and Foetal Bio-Physiological Parameters Among Antenatal Women Undergoing Non Stress Test in Tertiary Care Hospital of Patiala,

Punjab

\section{Section B}

\subsection{Assess the baseline maternal foetal bio-physiological parameters}

Table 2 shows that in baseline position the SBP Mean \pm SD was $115.8 \pm 8.3$ and $121.8 \pm 10.2$ with the range 110-140 and 108-150 in experimental group I and II respectively. DBP with Mean \pm SD was $74.5 \pm 7.7$ and $78.5 \pm 8.1$ with the range 60-90 and 70-100. PR with Mean \pm SD was $83.8 \pm 7.6$ and $84.3 \pm 6.7$ with the range 74-94 and 74-94. RR with Mean \pm SD was $20.0 \pm$ 0.7 and $20.4 \pm 1.3$ with the range 18-22 and 20-22 in experimentalgroup I and II respectively.

$$
\mathbf{N}=\mathbf{3 0}+\mathbf{3 0}
$$

Table 2: Comparison of baseline(supine) score of maternal bio-physiological parameters among Experiment group I and II.

\begin{tabular}{ccccc}
\hline Parameters & Experiment I & Experiment II & \\
\hline & Range & Mean + SD & Range & Mean + SD \\
Systolic blood pressure & $110-140$ & $115.8+8.3$ & $108-150$ & $121.8+10.2$ \\
Diastolic blood pressure & $60-90$ & $74.5+7.7$ & $70-100$ & $78.5+8.1$ \\
$\quad$ Pulse rate/ min & $74-94$ & $83.8+7.6$ & $74-94$ & $84.3+6.7$ \\
Respiration rate/min & $18-22$ & $20.0+0.7$ & $20-22$ & $20.4+1.3$ \\
\hline
\end{tabular}


Kaur, G

Narula, P

Kaur, H

Table 3 depicts in baseline position baseline heart rate between 110-150 bpm was present in 29(96.7) and absent in 1(3.3) in experimental I and II respectively. Two or more acceleration in baseline position in experimental group I was present in 6(20.0) and absent in 24(80.0) whereas in experimental group II was present in 5(16.7) and absent in 25(83.3). Foetal heart rate deceleration in baseline position in experimental group I was present in 26(86.7) and absent in 4(13.3) whereas in experimental group II was present in 27(90.0) and absent in 3(10.0). Foetal movement in baseline position in experimental group I was present in 16(53.3) and absent in 14(46.7) whereas in experimental group II was present in 11(36.7) and absent in 19(63.3).

$$
\mathbf{N}=\mathbf{3 0}+\mathbf{3 0}
$$

Table 3: Comparison of baseline(supine) score of foetal bio-physiological parameters among Experiment group I and II.

\begin{tabular}{|c|c|c|c|c|}
\hline \multirow[t]{3}{*}{ Parameters } & \multicolumn{2}{|c|}{ Experiment I } & \multicolumn{2}{|c|}{ Experiment II } \\
\hline & Yes & No & Yes & No \\
\hline & $\mathrm{f}(\%)$ & $\mathrm{f}(\%)$ & $\mathrm{f}(\%)$ & $\mathrm{f}(\%)$ \\
\hline $\begin{array}{l}\text { Baseline heart rate between } 110 \text { - } \\
150 \text { bpm with moderate variability } \\
(5-25 \text { inter beat variability) }\end{array}$ & 29(96.7) & $1(3.3)$ & 29(96.7) & $1(3.3)$ \\
\hline $\begin{array}{l}\text { Two or more accelerations of more } \\
\text { than } 15 \text { bpm above the baseline and } \\
\text { longer for } 15 \text { seconds within } 10 \\
\text { minute period }\end{array}$ & $6(20.0)$ & $24(80.0)$ & $5(16.7)$ & $25(83.3)$ \\
\hline Foetal heart rate deceleration & $26(86.7)$ & $4(13.3)$ & $27(90.0)$ & $3(10.0)$ \\
\hline Foetal movement & $16(53.3)$ & $14(46.7)$ & $11(36.7)$ & $19(63.3)$ \\
\hline
\end{tabular}

\section{Section C}

\subsection{Compare baseline score of maternal foetal bio-physiological parameters with semi-sitting and left lateral score.}

$\mathrm{H}_{01}$-There is no significant difference of baseline position with semi-sitting versus left lateral position on maternal and foetal bio-physiological parameters among antenatal women undergoing non stress test. 
$\mathrm{H}_{1}$-There is significant difference of baseline position with semi-sitting versus left lateral position on maternal and foetal bio-physiological parameters among antenatal women undergoing non stress test.

Table 4 depicts that in baseline and semi-sitting position Mean $\pm \mathrm{SD}$ of SBP was $115 \pm 8.3,118.7 \pm 4.3$ with -2.9 mean difference. Mean \pm SD of DSP was $74.5 \pm 7.7,77.4 \pm 4.8$ with -2.9 mean difference. Mean \pm SD of PR was $83.8 \pm 7.6$ and $81.2 \pm 7.5$ with -2.6 mean difference. Mean \pm SD of RR was $20.0 \pm 0.7$ and $20.2 \pm 0.6$ with -0.2 mean difference in baseline and semi-sitting position respectively. Calculated t value of all parameters was more than tabulated value. So, Semi-sitting had significant effect on maternal bio-physiological parameters at $\mathrm{p}<0.05$ level of significance. Hence research hypothesis was accepted.

$\mathbf{N}=\mathbf{3 0}$

Table 4: Comparison of baseline(supine) with semi-sitting score of maternal bio-physiological parameters among Experiment group I.

\begin{tabular}{crrrl}
\hline Parameters & $\begin{array}{r}\text { Baseline } \\
\text { Mean } \pm \text { SD }\end{array}$ & $\begin{array}{c}\text { Semi-sitting } \\
\text { Mean } \pm \text { SD }\end{array}$ & $\begin{array}{l}\text { Mean } \\
\text { difference }\end{array}$ & 't' \\
\hline $\begin{array}{c}\text { Systolic blood } \\
\text { pressure }\end{array}$ & $115.8 \pm 8.3$ & $118.7 \pm 4.3$ & -2.9 & $-2.404^{*}$ \\
& & & & \\
$\begin{array}{c}\text { Diastolic blood } \\
\text { pressure }\end{array}$ & $74.5 \pm 7.7$ & $77.4 \pm 4.8$ & -2.9 & $-3.515^{* *}$ \\
$\begin{array}{c}\text { Pulse rate/min } \\
\text { Respiration rate/ } \\
\text { min }\end{array}$ & $83.8 \pm 7.6$ & $81.2 \pm 7.5$ & -2.6 & $5.204^{* * *}$ \\
\hline
\end{tabular}

df-29*Significant at $\mathrm{p}<0.05$

Table 5 depicts that semi-sitting position when compared with baseline position had significant effect on acceleration and foetal movement whereas had no significant effect on baseline heart rate and foetal heart rate deceleration. So semi-sitting had significant effect on foetal bio-physiological parameters except baseline heart rate and deceleration at $\mathrm{p}<0.05$ level of significance. Hence research hypothesis was accepted.

$\mathbf{N}=\mathbf{3 0}$
A Quasi

Experimental Study to Compare the Effect of SemiSitting Versus Left Lateral Position on Maternal and Foetal Bio-Physiological Parameters Among Antenatal Women Undergoing Non Stress Test in Tertiary Care Hospital of Patiala, Punjab 
Kaur, G Narula, P

Kaur, $\mathrm{H}$
Table 5: Comparison of baseline(supine) with semi-sitting score of foetal bio-physiological parameters among Experiment group I.

\begin{tabular}{llllll}
\hline Parameters & Baseline & & \multicolumn{2}{l}{ Semi-sitting } & \\
\hline & Yes & No & Yes & No & $X^{2}$ \\
\hline & $\mathbf{f}(\%)$ & $\mathbf{f}(\%)$ & $\mathbf{f}(\%)$ & $\mathbf{f}(\%)$ &
\end{tabular}

Baseline heart rate between $110-150 \mathrm{bpm}$ with moderate variability (5-25 inter beat $29(96.7) \quad 1(3.3) \quad 29(96.7) \quad 1(3.3) \quad 0.517^{\mathrm{NS}}$ variability)

Two or more accelerations of more than $15 \mathrm{bpm}$ above the baseline and longer for 15 seconds within 10 minute $6(20.0) \quad 24(80.0) \quad 22(73.3) \quad 8(26.7) \quad 17.143^{*}$ period

Foetal heart rate deceleration

Foetal movement

$$
\begin{array}{lllll}
26(86.7) & 4(13.3) & 24(80.0) & 6(20.0) & 0.483^{\mathrm{NS}} \\
16(53.3) & 14(46.7) & 24(80.0) & 6(20.0) & 4.8^{*}
\end{array}
$$

$\mathrm{df}=1,{ }^{*}$ Significant at $\mathrm{p}<0.05$

$\mathrm{NS}=$ non significant

Table 6 depicts that in baseline and left lateral position Mean \pm SD of SBP was $121.8 \pm 10.2,120.6 \pm 5.8$ with 1.2 mean difference. Mean \pm SD of DSP was $78.5 \pm 8.1,77.6 \pm 5.8$ with 0.9 mean difference. Mean \pm SD of PR was $84.3 \pm 6.7$ and $82.2 \pm 6.0$ with 2.1 mean difference. Mean \pm SD of RR was $20.4 \pm 1.3$ and $20.4 \pm 0.8$ with 0 mean difference in baseline and left lateral position respectively. Calculated t value of all parameters except pulse rate was less than tabulated value.So left lateral had no significant effect on maternal bio-physiological parameters except on pulse rate at $\mathrm{p}<0.05$ level of significance. Hence null hypothesis was accepted.

Table 6: Comparison of baseline(supine) with left lateral score of maternal bio-physiological parameters among Experiment group II.

\begin{tabular}{lccll}
\hline Parameters & Baseline & Left-lateral & \\
& Mean \pm SD & Mean \pm SD & $\begin{array}{l}\text { Mean } \\
\text { difference }\end{array}$ & ' $\mathbf{~}$ ' \\
\hline $\begin{array}{l}\text { Systolic blood } \\
\text { pressure }\end{array}$ & $121.8 \pm 10.2$ & $120.6 \pm 5.8$ & 1.2 & $0.978^{\text {NS }}$ \\
\hline
\end{tabular}


Diastolic blood

pressure

Pulse rate/min

$84.3 \pm 6.7 \quad 82.2 \pm 6.0$

2.1

$6.440^{* * *}$

Respiration rate/min

$20.4 \pm 1.3$

$20.4+0.8$

0

$0.273^{\mathrm{NS}}$
NS= non significant

Table 7 depicts that left lateral position when compared with baseline position had significant effect on acceleration and foetal movement whereas had no significant effect on baseline heart rate and foetal heart rate deceleration. So left lateral had significant effect on foetal bio-physiological parameters except baseline heart rate and deceleration at $\mathrm{p}<0.05$ level of significance. Hence research hypothesis was accepted.
A Quasi

Experimental Study to Compare the Effect of SemiSitting Versus Left Lateral Position on Maternal and Foetal Bio-Physiological Parameters Among Antenatal Women Undergoing Non Stress Test in Tertiary Care Hospital of Patiala,

Punjab

Table 7: Comparison of baseline(supine) with left lateral score of foetal biophysiological parameters among Experiment group II.

\begin{tabular}{llllll}
\hline Parameters & \multicolumn{2}{c}{ Baseline } & \multicolumn{3}{c}{ Left lateral } \\
& Yes & No & Yes & No & X2 \\
\hline & $\mathbf{f}(\%)$ & $\mathbf{f}(\%)$ & $\mathbf{f}(\%)$ & $\mathbf{f}(\%)$ & \\
\hline
\end{tabular}

Baseline heart rate between $110-150 \mathrm{bpm}$ with moderate $29(96.7) \quad 1(3.3) \quad 30(100.0) \quad 0(0.0) \quad 0.000^{\mathrm{NS}}$ variability (5-25 inter beat variability)

Two or more accelerations of more than $15 \mathrm{bpm}$ above the baseline and longer for 15 seconds within 10 minute $5(16.7) \quad 25(83.3) \quad 23(76.7) \quad 7(23.3) \quad 21.696^{*}$ period

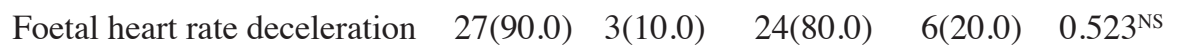

Foetal movement

$$
\begin{array}{lllll}
11(36.7) & 19(63.3) & 27(90.0) & 3(10.0) & 18.373^{*}
\end{array}
$$


Kaur, G

Narula, $P$

Kaur, $\mathrm{H}$

\section{Section D}

\subsection{Compare the maternal foetal bio-physiological parameters among experimental group I and II}

$\mathrm{H}_{02}$-There will be no significant difference between semi-sitting versus left lateral position on maternal and foetal bio-physiological parameters among antenatal women undergoing non stress test .

$\mathrm{H}_{2}$-There is significant difference between semi-sitting versus left lateral position on maternal and foetal bio-physiological parameters among antenatal women undergoing non stress test .

Table 8 depicts that in semi-sitting and left lateral Mean \pm SD of SBP was $118 \pm 4.3,120.6 \pm 5.8$ with -1.9 mean difference. Mean \pm SD of DSP was $74.4 \pm 4.8,77.6 \pm 5.8$ with -0.2 mean difference. Mean \pm SD of PR was $81.2 \pm 7.5$ and $82.2 \pm 6.0$ with -1 mean difference. Mean \pm SD of RR was $20.2 \pm 0.6$ and $20.4 \pm 0.8$ with -0.2 mean difference. Calculated $t$ value of all parameters was less than tabulated value. So semi-sitting versus left lateral had no significant effect on maternal bio-physiological parameters at $\mathrm{p}<0.05$ level of significance. Hence null hypothesis was accepted.

$$
\mathbf{N}=\mathbf{3 0}+\mathbf{3 0}
$$

Table 8: Comparison of semi-sitting versus left lateral position on maternal bio-physiological parameters among experiment I and II .

\begin{tabular}{|c|c|c|c|c|}
\hline \multirow[t]{2}{*}{ Parameters } & \multicolumn{4}{|c|}{ Experiment I Experiment II } \\
\hline & $\operatorname{Mean} \pm \mathbf{S D}$ & $\begin{array}{l}\text { Mean } \pm \\
\text { SD }\end{array}$ & $\begin{array}{l}\text { Mean } \\
\text { difference }\end{array}$ & t-value \\
\hline & $118 \pm 4.3$ & $120.6 \pm 5.8$ & -1.9 & $-1.448^{\mathrm{NS}}$ \\
\hline
\end{tabular}

Systolic blood

pressure

$$
\begin{array}{llll}
74.4 \pm 4.8 & 77.6 \pm 5.8 & -0.2 & -0.096^{\mathrm{NS}}
\end{array}
$$

Diastolic blood

pressure

$$
\begin{array}{llll}
81.2 \pm 7.5 & 82.2 \pm 6.0 & -1 & -0.565^{\mathrm{NS}}
\end{array}
$$

Pulse rate/min

$$
20.2 \pm 0.6 \quad 20.4 \pm 0.8 \quad-0.2 \quad-0.684^{\mathrm{NS}}
$$

Respiration rate/min 
$\mathrm{H}_{3}$ - There is association of maternal and foetal bio-physiological parameters among antenatal women undergoing non stress test with selected demographic variable.

$\mathbf{N}=\mathbf{3 0}+\mathbf{3 0}$

Table 9: Comparison of semi-sitting versus left lateral position on foetal biophysiological parameters among experiment I and II.

\begin{tabular}{llllll}
\hline Parameters & \multicolumn{4}{l}{ Semi-sitting } & \multicolumn{2}{l}{ Left lateral } & \\
\hline Yes & No & Yes & No & X2 \\
\hline & $\mathbf{f}(\%)$ & $\mathbf{f}(\%)$ & $\mathbf{f}(\%)$ & $\mathbf{f}(\%)$ &
\end{tabular}

Baseline heart rate between $110-150 \mathrm{bpm}$ with moderate variability $(5-25$ inter beat $29(96.7) \quad 1(3.3) \quad 30(100.0) \quad 0(0.0) \quad 1.017^{\mathrm{NS}}$ variability)

Two or more accelerations of more than $15 \mathrm{bpm}$ above the baseline and longer for 15 seconds within 10 minute $\begin{array}{lllll}22(73.3) & 8(26.7) & 23(76.7) & 7(23.3) & 0.089^{\mathrm{NS}}\end{array}$ period

Foetal heart rate deceleration

Foetal movement

$\overline{\mathbf{d f}}=\mathbf{1}$ 24(80.0) 6(20.0) 24(80.0) $6(20.0) \quad 0.000^{\mathrm{NS}}$ $\begin{array}{lllll}24(80.0) & 6(20.0) & 27(90.0) & 3(10.0) & 1.176^{\mathrm{NS}}\end{array}$
A Quasi Experimental Study to Compare the Effect of SemiSitting Versus Left Lateral Position on Maternal and Foetal Bio-Physiological Parameters Among Antenatal Women Undergoing Non Stress Test in Tertiary Care Hospital of Patiala,

Punjab

Table 9: depicts that semi-sitting versus left lateral had no significant effect on foetal bio-physiological parameters at $\mathrm{p}<0.05$ level of significance. Hence null hypothesis was accepted.

\section{Section D}

\subsection{Association of maternal foetal bio-physiological parameters with selected demographic variables}

$\mathrm{H}_{03}$-There is no association of maternal and foetal bio-physiological parameters among antenatal women undergoing non stress test with selected demographic variable. 


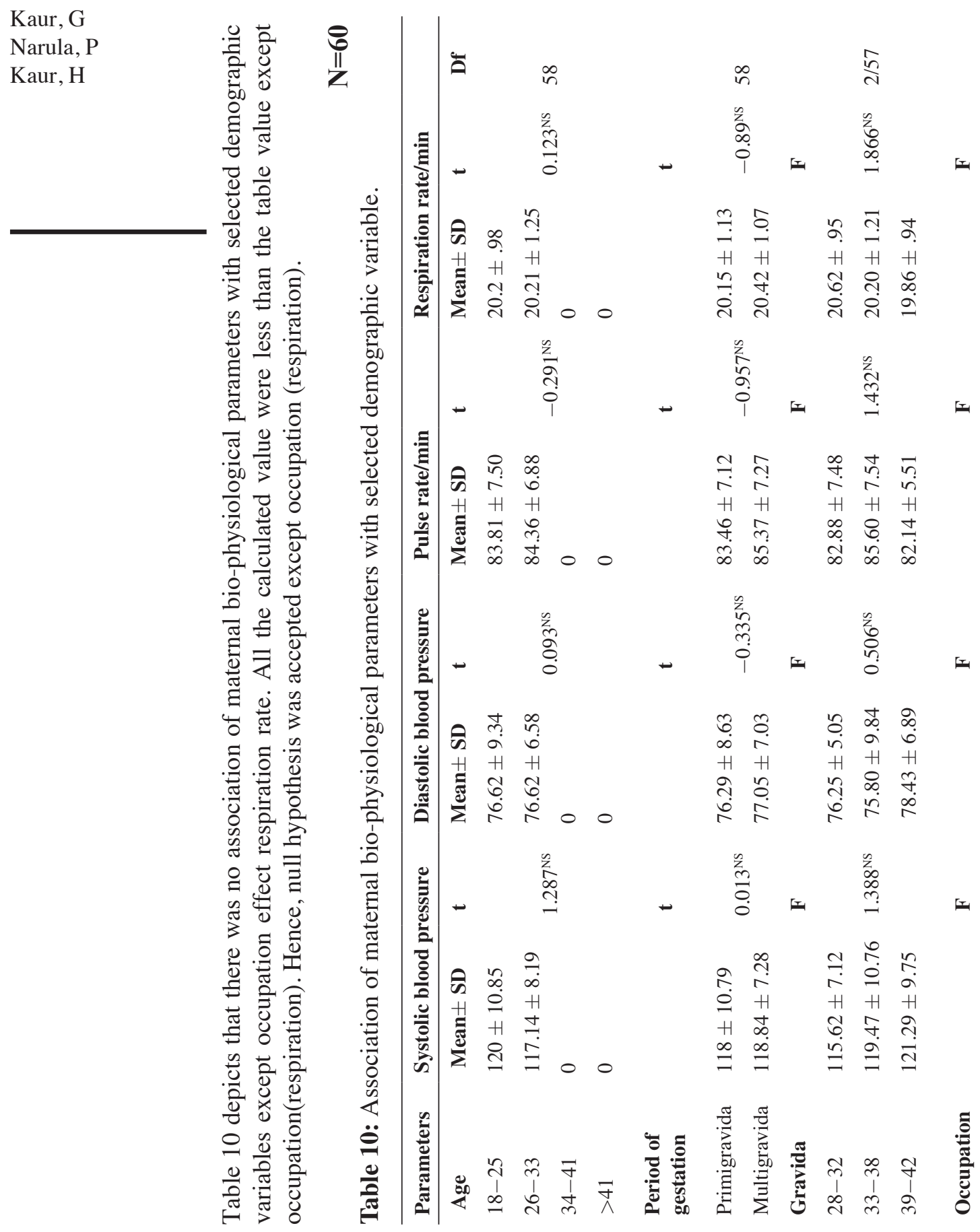




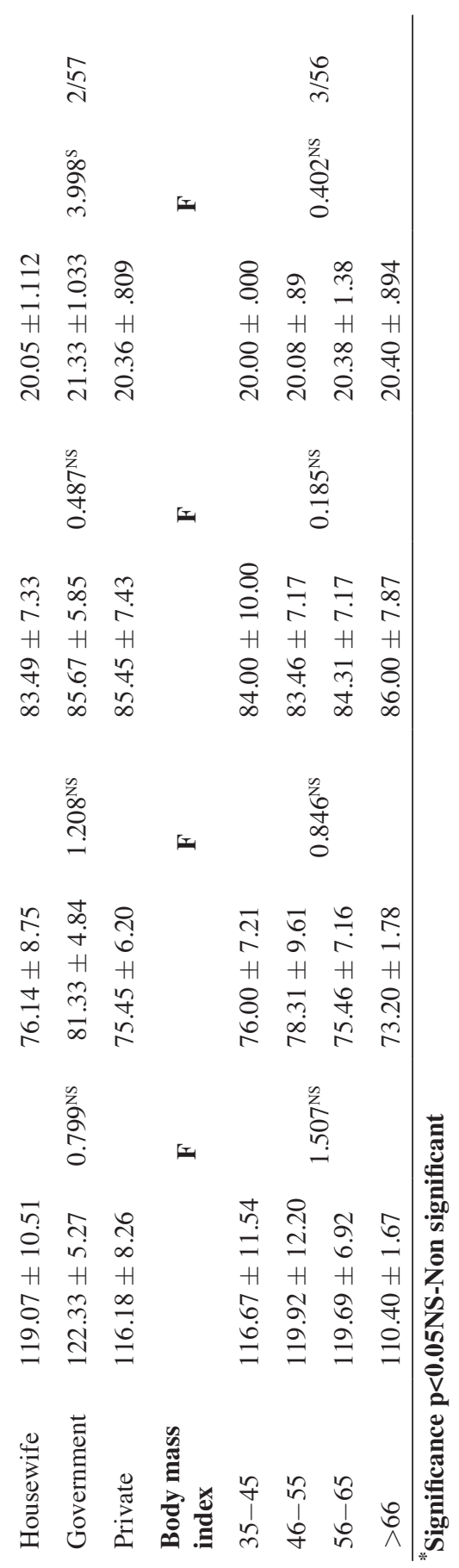

A Quasi

Experimental Study to Compare the Effect of SemiSitting Versus Left Lateral Position on Maternal and Foetal Bio-Physiological Parameters Among Antenatal Women Undergoing Non Stress Test in Tertiary Care Hospital of Patiala, Punjab 
Kaur, G Narula, P

Kaur, $\mathrm{H}$
Table 11 depicts that there was no association of foetal bio-physiological parameters with selected demographic variables except period of gestation effect foetal movement. All the calculated value were less than the table value except period of gestation (foetal movement). Hence, null hypothesis was accepted except period of gestation (foetal movement).

Table 11: Association of foetal bio-physiological parameters with selected demographic variable.

\begin{tabular}{|c|c|c|c|c|c|c|c|c|c|c|c|c|c|}
\hline \multirow{2}{*}{$\begin{array}{l}\text { Parameters } \\
\qquad \text { Age }\end{array}$} & \multicolumn{3}{|c|}{$\begin{array}{c}\text { Baseline heart } \\
\text { rate }\end{array}$} & \multicolumn{3}{|c|}{ Acceleration } & \multicolumn{3}{|c|}{ Deceleration } & \multicolumn{3}{|c|}{$\begin{array}{c}\text { Foetal } \\
\text { movement }\end{array}$} & \multirow[b]{2}{*}{ Df } \\
\hline & Yes & No & $X^{2}$ & Yes & No & $X^{2}$ & Yes & No & $X^{2}$ & Yes & No & $X^{2}$ & \\
\hline $18-25$ & 30 & 2 & \multirow{4}{*}{$1.81^{\mathrm{NS}}$} & 4 & 28 & \multirow{4}{*}{$1.558^{\mathrm{NS}}$} & 27 & 5 & & 12 & 20 & \multirow{4}{*}{$1.558^{\mathrm{NS}}$} & \multirow{4}{*}{1} \\
\hline $26-33$ & 28 & 0 & & 7 & 21 & & 26 & 2 & 1012 NS & 15 & 13 & & \\
\hline $34-41$ & 0 & 0 & & 0 & 0 & & 0 & 0 & & 0 & 0 & & \\
\hline$>41$ & 0 & 0 & & 0 & 0 & & 0 & 0 & & 0 & 0 & & \\
\hline \multicolumn{14}{|l|}{$\begin{array}{l}\text { Period of } \\
\text { gestation }\end{array}$} \\
\hline $28-32$ & 15 & 1 & & 1 & 15 & & 15 & 1 & $0.63^{\mathrm{NS}}$ & 4 & 12 & & \\
\hline $33-38$ & 29 & 1 & $0.905^{\mathrm{NS}}$ & 6 & 24 & $2.596^{\mathrm{NS}}$ & 26 & 4 & & 13 & 17 & $6.57^{*}$ & 2 \\
\hline $39-42$ & 14 & 0 & & 4 & 10 & & 12 & 2 & & 10 & 4 & & \\
\hline
\end{tabular}

\section{Gravida}

$\begin{array}{llllllllllllll}\text { Primigravida } & 39 & 2 & & & 8 & 33 & & 36 & 5 & & 18 & 23 & \\ \text { Multigravida } & 19 & 0 & 0.959^{\mathrm{NS}} & 3 & 16 & 0.12^{\mathrm{NS}} & 17 & 2 & 0.035^{\mathrm{NS}} & 9 & 10 & 0.063^{\mathrm{NS}} & 1\end{array}$

\section{Occupation}

\begin{tabular}{|c|c|c|c|c|c|c|c|c|c|c|c|c|}
\hline Housewife & 42 & 1 & & 8 & 35 & & 36 & 7 & & 22 & 21 & \\
\hline Government & 5 & 1 & $3.825^{\mathrm{NS}}$ & 0 & 6 & $1.936^{\mathrm{NS}}$ & 6 & 0 & $3.133^{\mathrm{NS}}$ & 1 & 5 & $2.937^{\mathrm{NS}}$ \\
\hline Private & 11 & 0 & & 3 & 8 & & 11 & 0 & & 4 & 7 & \\
\hline
\end{tabular}

Body mass index

\begin{tabular}{|c|c|c|c|c|c|c|c|c|c|c|c|c|c|}
\hline $35-45$ & 3 & 0 & \multirow{3}{*}{$2.706^{\mathrm{NS}}$} & 0 & 3 & & 2 & 1 & & 2 & 1 & \multirow{3}{*}{$1.331^{\mathrm{NS}}$} & \\
\hline $46-55$ & 24 & 2 & & 4 & 22 & $1224^{\mathrm{NS}}$ & 21 & 5 & $5013^{\mathrm{NS}}$ & 13 & 13 & & 3 \\
\hline $56-65$ & 26 & 0 & & 6 & 20 & & 25 & 1 & & 10 & 16 & & \\
\hline$>66$ & 5 & 0 & & 1 & 4 & & 5 & 0 & & 2 & 3 & & \\
\hline
\end{tabular}

"Significance $\mathbf{p}<0.05 \quad$ NS-Non significant 


\section{DISCUSSION}

The present study intends to compare the effect of semi-sitting versus left lateral position on maternal and foetal bio-physiological parameters among antenatal women undergoing non stress test in Tertiary Care Hospital of Patiala, Punjab.

The present study depicts that semi-sitting when compared with left lateral had no significant effect on maternal and foetal bio-physiological parameters .Calculated ' $t$ ' value of all parameters was less than tabulated value. So semisitting versus left lateral had no significant effect on maternal foetal biophysiological parameters at $(\mathrm{p}<0.05)$ level of significance.

These findings are in accordance with the study done by ManeeshaMS $\mathbf{M S}^{27}$, to assess the effect of maternal position on physiological parameters of antenatal mothers and fetus during non stress test. There was no significant difference in ' $F$ ' value for physiological parameters maternal(pulse, respiration, systolic and diastolic pressure) and foetal (fetal heart rate, movement, acceleration) during the test . All the calculated values for the maternal and foetal physiological parameters were less than the tabulated value, so the researcher accepted the null hypothesis.

These findings are congruent with the study done by Samuel $\mathbf{R}^{9}$ to compare the materno foetal physiological parameters during non stress test. There were significant changes in maternal bio-physiological parameters like maternal systolic, diastolic blood pressure, pulse rate between left lateral and sitting position at $(\mathrm{p}<0.01)$ level of significance. There was significant difference in foetal physiological parameters like baseline foetal heart rate $(\mathrm{p}=0.034)$ and deceleration $(\mathrm{p}<0.001)$ between sitting and left lateral position.

The present study depicts that there is no significant association of demographic variable i.e age, period of gestation, body mass index with maternal foetal bio-physiological parameters at $(p<0.05)$ level of significance. These findings are in accordance with study conducted by Maneesha MS $^{8}$ regarding the effect of maternal positions on physical and physiological parameters of mother and fetus during non stress test. According to the result there was no significant association with selected demographic variables (age, period of gestation, body mass index) at $\mathrm{p}<0.05$ level of significance.

\section{CONCLUSION}

The result concluded that baseline position(supine) when altered to semisitting position influenced the maternal foetal bio-physiological parameters whereas baseline position(supine) when altered to left lateral position influenced the maternal (pulse rate) and foetal (acceleration, foetal movement)
A Quasi

Experimental Study to Compare the Effect of SemiSitting Versus Left Lateral Position on

Maternal and Foetal

Bio-Physiological

Parameters Among

Antenatal Women

Undergoing Non

Stress Test in

Tertiary Care

Hospital of Patiala,

Punjab

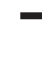

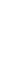


Kaur, G

Narula, $P$

Kaur, $\mathrm{H}$

bio-physiological parameters. Semi-sitting when compared with left lateral had no significant effect on maternal and foetal bio-physiological parameters.

Ethical Clearance:The study was conducted after approval by the institutional Ethics Committee

\section{REFERENCES}

[1] Neeson JD, May KA. Comprehensive maternity nursing process and the child bearing family. London: lipponcott; 1986.

[2] American pregnancy association: Fetal non stress test [Internet]. 2008 [cited 2015 July 7]. Available from: http://www.americanpregnancy.org>prenatal-testing.

[3] Gearhart PA. Ultrasonography Biophysical profile [Internet]. 2008 [cited 2015 Jan 6]. Available from: http://emedicine medscape.com/article/405454-overview. Dorothy Marlow's.Textbook of Pediatric Nursing. $6^{\text {th }}$ ed. Philadelphia : W.B. Saunder's publications, 1988:773-74

[4] Alus M, Okumus H, Mete S and Guclu S. The effect of different maternal position on non stresstest :An experimental study. JCN [Internet]. 2007 Mar [cited 2015 Feb 8]; 16(3):562-68. Available from: http://www.ncbi.nlm.nih.govpmid:17335532.

[5] Cito G. Maternal position during non-stress and foetal heart rate patterns. Actaobstetgynecolscand [Internet]. 2005 [cited 2015 Jan 23]; 63(6)84:335-8. Available from: http:// www.ncbi.nih.gov/pubmed/15762962.

[6] Nathan EB, Haberman S, Burgess T, Minkoff H. The relationship of maternal position to the result of brief non stress test: A randomized clinical trial. Journal of obstetrics and gynaecology [Internet]. 2000 [cited 2015 Oct 19]; 13(2):86-9. Available from URL: http:// www.ncbi.nlm.nih.gov/pmc/articles PMC326789.

[7] Lorzadeh N, Kazemirad S. Evaluation of the result of non stress test in two position in high risk pregnancies. UOG [Internet]. 2011Sep 14 [cited $2015 \mathrm{Jan}$ 5]; 38(3):168-81. Available from:http:// onlinelibrary.wiley.com.uog.9797.

[8] Maneesha MS. A study to assess the effect of maternal position on physical and physiological parameters of antenatal mother and foetal during non stress test at kollam, kerala. NJOE [Internet]. 2013 [cited 2014 Dec 13]; 3(4):853-56. Available from: http://www.nepjol.info $>$ NJE $>$ article

[9] Samuel R, Karkada S, Fernandes S, Bhat P. Materno foetal physiological parameters in sitting and left lateral position during non stresstest(NST) monitoring in pregnancy: A cross over study. MJNHS [Internet]. 2015 July [cited from 2016 Dec 6]; 1(2):83-6. Available from: http://ejounal.manipal.edu>mjn. 